
VOLUME 10 NOMOR 6 DESEMBER 2021

ISSN : 2303-1514 | E-ISSN : 2598-5949

\title{
PENGARUH MEDIA WAYANG SUKURAGA TERHADAP KETERAMPILAN MENULIS DESKRIPSI PADA SISWA KELAS TINGGI SEKOLAH DASAR
}

\author{
Nawaliyatul Hilwa $^{1}$, Iis Nurasiah ${ }^{2}$, Dyah Lyesmaya $^{3}$ \\ ${ }^{1,2,3}$ Universitas Muhammadiyah Sukabumi, Sukabumi, Indonesia \\ 1Hilwanawaliyatul@gmail.com2iisnurasiah@ummi.ac.id3lyesmaya_dyah@ummi.ac.id
}

\section{THE INFLUENCE OF SUKURAGA PUPPET MEDIA ON STUDENTS' WRITING DESCRIPTION SKILLS IN UPPER CLASSES OF ELEMENTARY SCHOOL}

\begin{tabular}{|c|c|}
\hline ARTICLE HISTORY & ABSTRACT \\
\hline $\begin{array}{l}\text { Submitted: } \\
\text { 08 Juni } 2021 \\
\text { 08 } 8^{\text {th }} \text { June } 2021\end{array}$ & $\begin{array}{l}\text { Abstract: This study aimed to determine the effect of the Sukuraga puppet media on students' } \\
\text { descriptive writing skills in upper classes of elementary school. The type of research was } \\
\text { Quasi-Experimental design with a Nonequivalent Control Group Design. The population of } \\
\text { this research was the fifth-grade students of Madrasah Ibtidaiyah Rambay in the } 2020 / 2021 \\
\text { academic year. The samples were determined by saturated sampling. The samples of this study } \\
\text { were } 20 \text { students from class } V \text { B as the experimental group and } 20 \text { students from class V A as } \\
\text { the control group. The descriptive writing skills research data resulted from the instrument in } \\
\text { the form of a test that explained one thing that had been validated. Data of the skills described } \\
\text { the analysis by using a two-sample independent T-test. The test results produced a sig value of } \\
0.025 \text {, smaller than } 0.05 \text {. Thus, Ho was rejected, H } H_{I} \text { was accepted. These results indicated } \\
\text { significant differences between the experimental class and the control class. The Sukuraga } \\
\text { puppet media affected students' descriptive writing skills. }\end{array}$ \\
\hline
\end{tabular}

Keywords: puppet sukuraga, descriptive writing skills

Accepted:

22 Oktober 2021

$22^{\text {th }}$ October 2021
Abstrak: Penelitian ini bertujuan untuk mengetahui pengaruh media wayang sukuraga terhadap keterampilan menulis deskripsi pada siswa kelas tinggi sekolah dasar. Jenis penelitian yang digunakan yaitu Quasi Experimental designs dan desain penelitian Nonequivalent Control Group Design. Populasi penelitian ini yaitu siswa kelas V Madrasah Ibtidaiyah Rambay tahun ajaran 2020/2021. Sampel ditentukan dengan sampling jenuh. Sampel penelitian ini yaitu kelas V B sebagai kelompok eksperimen berjumlah 20 siswa dan kelas V A sebagai kelompok kontrol berjumlah 20 siswa. Data hasil penelitian keterampilan menulis deskripsi dihasilkan dari instrumen berupa tes uraian yang berjumlah satu soal yang telah divalidasi. Data keterampilan menulis deskripsi dianalisis dengan menggunakan uji T dua sampel independen. Hasil uji tersebut menghasilkan nilai sig. 0.025 nilai tersebut lebih kecil dari 0.05 artinya $\mathrm{H}_{0}$ ditolak $\mathrm{H}_{1}$ diterima. Berdasarkan hasil tersebut dapat disimpulkan terdapat perbedaan yang signifikan antara kelas eksperimen dan kelas kontrol. Media wayang sukuraga berpengaruh terhadap keterampilan menulis deskripsi siswa.

Published: 27 Desember 2021 $27^{\text {th }}$ December 2021
Kata kunci: wayang sukuraga, keterampilan menulis deskripsi

\section{CITATION}

Hilwa, N.. Nurasiah, I., \& Lyesmaya, D. (2021). Pengaruh Media Wayang Sukuraga Terhadap Keterampilan Menulis Deskripsi Pada Siswa Kelas Tinggi Sekolah Dasar. Primary: Jurnal Pendidikan Guru Sekolah Dasar, 10 (6), 1482-1489. DOI: http://dx.doi.org/10.33578/jpfkip.v10i6.8428.

\section{PENDAHULUAN}

Pembelajaran bahasa Indonesia wajib diberikan dalam dunia pendidikan baik pendidikan dasar, menengah, maupun perguruan tinggi. Bahasa Indonesia memiliki empat keterampilan berbahasa salah satunya yaitu keterampilan menulis. Keterampilan menulis sangat penting diajarkan sejak anak di sekolah dasar karena dapat mengembangkan intelektual, gagasan, dan ide anak. 
Keterampilan menulis deskripsi yaitu sebuah teks yang menggambarkan tentang peristiwa, objek, tokoh, dan tempat secara mendalam dan jelas sehingga pembaca seolah-olah merasakan langsung apa yang dideskripsikan.

Keberhasilan menulis deskripsi dipengaruhi oleh kemampuan guru serta bantuan media pembelajaran yang digunakan dalam menggambarkan suatu objek yang dideskripsikan. Peran guru dalam melaksanakan pembelajaran serta media yang digunakan untuk menulis deskripsi dapat mempengaruhi hasil menulis deskripsi siswa. Pada kenyataannya ketika melaksanakan pembelajaran tidak semua aspek keterampilan bahasa mudah untuk diajarkan kepada siswa termasuk keterampilan menulis. Hal itu disebabkan karena menulis kurang mendapat perhatian. Keterampilan menulis sangat perlu diajarkan kepada siswa sejak masih dibangku sekolah dasar agar siswa mampu menguasai kemampuan berbahasa dan dapat memahami tata bahasa serta ejaan yang tepat ketika membuat tulisan.

Keterampilan menulis deskripsi yaitu sebuah tulisan yang dihasilkan dari pengamatan panca indra untuk menciptakan dan menggambarkan sebuah objek secara detail dan mendalam sehingga pembaca bisa seolah-olah merasakan langsung apa yang dideskripsikan didalam tulisan. Menulis memiliki tujuan untuk melatih dan mengembangkan motorik halus siswa. Dengan menulis siswa dapat menggerakkan otot halus tangan siswa yang membuat siswa terampil dalam menulis. Sedangkan tujuan keterampilan menulis deskripsi yaitu tulisan yang mengambarkan secara detail tentang suatu objek sehingga dapat meningkatkan imajinasi dan memberi pengaruh emosi seolah-olah pembaca melihat, mendengar, dan merasakan secara langsung apa yang disampaikan penulis.

Manfaat keterampilan menulis deskripsi yaitu dapat mengetahui gambaran tentang suatu hal dan menjelaskan isi yang ada didalam teks kepada pembaca secara rinci agar pembaca ikut merasakan, melihat, mendengar apa yang diceritakan oleh penulis. Menulis tentu memiliki beberapa langkah atau tahapan karena menulis merupakan suatu proses. Menulis termasuk kedalam kegiatan yang dilakukan secara sistematis maka dari itu menulis harus dilakukan dengan langkah dan tahapan yang tersusun. langkah-langkah yang harus dilakukan seperti menentukan tema, merumuskan tujuan, mengamati objek yang akan dideskripsikan, menulis hasil pengamatan kedalam bentuk tulisan deskripsi. Dengan mengikuti langkah-langkah tersebut dapat menciptakan tulisan deskripsi yang tersusun dengan baik serta isi yang terkandung di dalamnya dapat di terima dan dipahami oleh pembaca seolah-olah pembaca dapat merasakan langsung objek yang diceritakan

Keterampilan menulis memiliki peran penting sebagai upaya dalam meningkatkan mutu pendidikan karena dengan menulis dapat mengungkapkan gagasan dan ide yang dimiliki siswa kedalam sebuah tulisan. Lailah, Fanani, \& Juniarso (2020: 197-198) mengungkapkan bahwa pada kenyataannya selama ini para siswa merasa kesulitan dalam membuat sebuah tulisan, kesulitan mereka dalam berimajinasi serta menuangkan ide-ide dalam bentuk tulisan sehingga menyebabkan beberapa siswa malas ketika menulis. Sejalan dengan pendapat tersebut Taufik Ismail dalam (Dhavita \& Damayanti, 2016: 162) mengatakan bahwa bangsa Indonesia masih rabun membaca dan lumpuh menulis, rata-rata siswa sekolah dasar belum mampu menulis secara mandiri dengan hasil yang memuaskan. Dalam membuat sebuah tulisan perlu latihan dan bimbingan dari guru agar dapat melatih kemampuan siswa untuk berpikir kreatif dalam mengolah kata, bahasa, ejaan serta dapat melatih siswa menemukan ide dan gagasan yang baru.

Media wayang lebih efektif digunakan ketika proses pembelajaran karena dengan media wayang membuat siswa lebih tertarik dan lebih bersemangat (Mila \& Anafiah, 2021: 1149). Dalam penelitian ini media wayang yang akan digunakan yaitu media wayang sukuraga. Media wayang sukuraga digunakan 
untuk mengetahui pengaruhnya terhadap keterampilan menulis deskripsi. Dengan menggunakan media wayang sukuraga diharapkan membantu siswa untuk mengamati objek yang akan dideskripsikan sesuai dengan pengamatan panca indra.

Wayang merupakan salah satu seni budaya bangsa Indonesia yang sudah ada sejak zaman dahulu. Wayang sering dijadikan sebagai sarana hiburan dalam sebuah acara pertunjukkan akan tetapi seiring berkembangnya zaman wayang dapat digunakan sebagai media pembelajaran. Wayang-wayang yang ada di Indonesia pada umumnya mengandung cerita yang berasal dari Hindu India seperti kisah Mahabrata dan Ramayana. Marsaid (2016: 108) berpendapat bahwa pada awal mula wayang menceritakan tentang tokoh para leluhur, legenda kepala suku, dan nenek moyang lambat laun diganti dengan cerita dewa hindu yaitu cerita wayang tentang kisah Mabahrata dan Ramayana. Wayang sukuraga memiliki perbedaan dengan wayang pada umumnya yang sudah berkembang di Indonesia. Wayang sukuraga tidak mengambil kisah dari Mahabrata dan Ramayana akan tetapi wayang sukuraga mengambil kisah dari kehidupan sehari-hari tentang kebiasaan manusia menggunakan anggota tubuh.

Ilina, Sutisnawati, \& Nurasiah (2020: 266) mengatakan bahwa wayang sukuraga dapat dijadikan sebagai media alternatif pembelajaran karena wayang sukuraga termasuk dalam media visual dua dimensi yang dapat dilihat serta dipegang. Media wayang sukuraga merupakan media yang nyata yang dapat dilihat dan dipegang dengan demikian, siswa dapat berinteraksi secara langsung dengan wayang sukuraga sehingga dapat menarik perhatian dan minat siswa dalam menulis deskripsi. wayang sukuraga mengandung nilai-nilai pembelajaran seperti nilai pendidikan karakter, nilai kebersamaan, nilai kepedulian dan nilai gotong royong yang baik untuk dikenalkan dan diajarkan sejak anak masih di sekolah dasar. siswa sekolah dasar pada tahap konkret operasional membutuhkan media yang nyata untuk dapat mengembangkan pemahaman dan membantu siswa dalam mengamati suatu objek terutama ketika siswa menulis teks deskripsi.

\section{KAJIAN TEORI}

Media wayang lebih efektif digunakan ketika proses pembelajaran karena dengan media wayang membuat siswa lebih tertarik dan lebih bersemangat (Mila \& Anafiah, 2021: 1149). Oktavianti \& Wiyanto (2014: 68) mengatakan bahwa media wayang merupakan media yang menarik karena selain mengajarkan kebudayaan bangsa Indonesia kepada siswa wayang juga dapat dijadikan sebagai media pembelajaran yang disesuaikan dengan materi yang akan dipelajari. Ilina, Sutisnawati, \& Nurasiah (2020: 266) yang mengatakan bahwa wayang sukuraga dapat dijadikan sebagai media alternatif pembelajaran karena wayang sukuraga termasuk dalam media visual dua dimensi yang dapat dilihat serta dipegang. Bentuk wayang sukuraga menurut Juliana, Nurasiah, \& Wardana (2019: 3) yaitu mata, hidung, mulut, telinga, tangan, dan kaki.

Suparno dalam (Ludvi \& Rukmi, 2013: 3) membagi tulisan kepada lima jenis yaitu narasi, deksripsi, eksposisi, argumentasi, dan persuasi. Nashruddin \& Damayanti (2013: 4) mengemukakan kata deskripsi berasal dari bahasa latin describere yang berarti menggambarkan atau memberikan suatu hal. Finoza dalam (Dalman, 2016: 93) mengemukakan tujuan menulis deksripsi untuk memperluas pengetahuan dan pengalaman pembaca dengan jalan melukiskan hakikat objek yang sebenarnya. Menulis memiliki beberapa manfaat yaitu dapat meningkatkan ide kecerdasan otak untuk terus berpikir dan bernalar, menemukan ide baru, dan dapat memecahkan suatu masalah (Halimatussakdiah, 2017: 159). Dalman (2016: 99) mengemukakan langkah-langkah menulis deksripsi sebagai berikut : Menentukan tema atau objek yang akan dideksripsikan, tentukan 
tujuan, mengumpulkan data dengan cara mengamati objek yang akan dideskripsikan, menyusun data tersebut kedalam urutan yang baik atau bisa juga membuat kerangka, menguraikan kerangka menjadi tulisan deksripsi yang sesuai dengan tema yang ditentukan.

\section{METODE PENELITIAN}

Penelitian ini menggunakan pendekatan penelitian kuantitatif jenis Quasi Experimental Designs. Penelitian eksperimen bertujuan untuk mengetahui pengaruh terhadap sampel. Desain penelitian ini menggunakan bentuk Nonequivalent Control Group Design. Tempat penelitian ini di Madrasah Ibtidaiyah (MI) Rambay. Penelitian dilaksanakan pada semester genap bulan Mei dan Juni tahun ajaran 2020/2021. Kedua kelas yang diteliti yaitu kelompok eksperimen dan kelompok kontrol sama-sama diberi pretest sebagai langkah awal lalu dicari hasilnya. Kemudian pada kelas eksperimen diberi tindakan yaitu menggunakan media wayang sukuraga, sedangkan pada kelas kontrol tidak diberi tindakan yaitu tidak menggunakan media wayang sukuraga. Setelah dilakukan tindakan maka kelas eksperimen dan kelas kontrol diberikan posttest untuk membuktikan pengaruh hasil setelah diberi tindakan.

Populasi pada penelitian ini yaitu siswa kelas VA dan VB MI Rambay tahun ajaran 2020/2021 yang berjumlah 40 siswa setiap kelas nya terdiri dari 20 siswa. Sampel penelitian ini ditentukan menggunakan teknik sampling yaitu sampling jenuh. Teknik pengumpulan data dalam penelitian ini yaitu menggunakan tes. Arikunto dalam Dhavita \& Damayanti (2016: 165) mengatakan bahwa tes merupakan susunan pertanyaan dan alat untuk mengukur pengetahuan, keterampilan, kemampuan yang dimiliki oleh individu atau kelompok.

Tabel 1. Kisi-kisi instrumen soal Keterampilan Menulis Deskrispsi

\begin{tabular}{|c|c|c|}
\hline Aspek & Indikator & Butir Item \\
\hline \multirow{4}{*}{$\begin{array}{l}\text { Menyajikan } \\
\text { kembali peristiwa } \\
\text { atau tindakan } \\
\text { dengan } \\
\text { memperhatikan } \\
\text { latar cerita yang } \\
\text { terdapat pada teks } \\
\text { fiksi } \\
\text { (Psikomotor) }\end{array}$} & Kesesuaian judul dengan isi & 1 \\
\hline & $\begin{array}{l}\text { Mendeskripsikan hasil pengamatan sesuai } \\
\text { panca indra }\end{array}$ & 1 \\
\hline & Organisasi Isi & 1 \\
\hline & Tata Bahasa dan Ejaan Yang Tepat & 1 \\
\hline
\end{tabular}

Tes yang dilakukan terbagi kepada dua yaitu pretest dan posttest. Pretest digunakan untuk mengukur dan mengetahui kemampuan siswa tentang menulis deksripsi di awal sebelum diberikan tindakan. posttest digunakan untuk mengukur kemampuan menulis deskripsi siswa di akhir setelah diberikan tindakan. Pretest dan posttest ini diberikan kepada siswa di kelas eksperimen dan kelas kontrol.
Perbandingan data pretest dan posttest yang dilakukan di kelas eksperimen dan kelas kontrol sebelum diberi tindakan. Untuk melakukan analisis pengujian data ini menggunakan uji paired-samples $\mathrm{T}$ test (uji $\mathrm{T}$ dua sampel berpasangan). Pengujian analisis data ini dilakukan jika data berasal dari subjek yang sama tetapi waktu dan teknik pengumpulan data yang berbeda. Uji hipotesis dilakukan untuk mengetahui tindakan yang berpengaruh di kelas eksperimen yang diberi 

VOLUME 10 NOMOR 6 DESEMBER 2021

ISSN : 2303-1514 | E-ISSN : 2598-5949

DOI : http://dx.doi.org/10.33578/jpfkip.v10i6.8428 https://primary.ejournal.unri.ac.id/index.php/JPFKIP

tindakan menggunakan wayang sukuraga dan di kelas kontrol yang tidak diberi tindakan wayang sukuraga. Hasil pengaruh dapat dilihat dari nilai posttest di kelas eksperimen dan di kelas kontrol. Kemudian untuk mengetahui hasil pengujian dapat dilakukan dengan menggunakan independent-samples $\mathrm{T}$ test (uji $\mathrm{T}$ dua sampel independen) dengan bantuan aplikasi SPSS 22. Taraf signifikan yaitu (sig) $a=5 \%$ atau 0.05 dengan kriteria uji yaitu jika sig $<a=5$ atau 0.05 maka Ho ditolak dan $\mathrm{H}_{1}$ diterima. Setelah melakukan uji hipotesis maka ditarik kesimpulan.

\section{HASIL DAN PEMBAHASAN}

Penelitian ini dilaksanakan sebanyak 2 kali pertemuan. Pertemuan pertama memberikan pretest untuk kedua kelas dan pertemuan kedua memberikan tindakan serta posttest tetapi pada jam yang berbeda.

Tabel 1. Hasil Analisis Nilai Posttest siswa

\begin{tabular}{|l|c|c|}
\hline \multicolumn{1}{|c|}{ Hasil Analisis } & Kelas Eksperimen & Kelas Kontrol \\
\hline $\mathrm{N}$ & 20 & 20 \\
\hline Rata-rata & 71.75 & 66.00 \\
\hline Skor minimal & 60 & 51 \\
\hline Skor Maksimal & 86 & 80 \\
\hline Simpangan Baku & 8.583 & 6.959 \\
\hline Varians & 73.671 & 48.421 \\
\hline
\end{tabular}

Pada kelas eksperimen mengalami peningkatan dan memiliki nilai rata-rata nilai posttest yang lebih tinggi dari nilai pretest hal ini karena pada kelas eksperimen menggunakan media wayang sukuraga pada saat proses pembelajaran. Setelah melakukan penelitian diperoleh hasil belajar siswa kelas eksperimen yang menggunakan media wayang sukuraga dengan menghasilkan rata-rata nilai posttest sebesar 71.75 sementara hasil belajar siswa kelas kontrol tanpa menggunakan media wayang sukuraga menghasilkan rata-rata nilai posttest sebesar 66.00 .

Tabel 2. Hasil Uji perbedaan Keterampilan Menulis Deskripsi Siswa

\begin{tabular}{|c|c|c|c|c|c|c|c|c|c|c|}
\hline & \multicolumn{2}{|c|}{$\begin{array}{l}\text { Levene's } \\
\text { Test for } \\
\text { Equality of } \\
\text { Variances }\end{array}$} & \multicolumn{7}{|c|}{ t-test for Equality of Means } \\
\hline & & \multirow[b]{2}{*}{$\mathrm{F}$} & \multirow[b]{2}{*}{ Sig. } & \multirow[b]{2}{*}{$\mathrm{T}$} & \multirow[b]{2}{*}{ Df } & \multirow{2}{*}{$\begin{array}{l}\text { Sig. } \\
(2- \\
\text { tailed) }\end{array}$} & \multirow{2}{*}{$\begin{array}{l}\text { Mean } \\
\text { Differ } \\
\text { ence }\end{array}$} & \multirow{2}{*}{$\begin{array}{l}\text { Std. } \\
\text { Error } \\
\text { Differ } \\
\text { ence }\end{array}$} & \multicolumn{2}{|c|}{$\begin{array}{c}95 \% \text { Confidence Interval } \\
\text { of the Difference }\end{array}$} \\
\hline & & & & & & & & & Lower & Upper \\
\hline Nilai Posttest & $\begin{array}{l}\text { Equal } \\
\text { variances } \\
\text { assumed } \\
\text { Equal } \\
\text { variances } \\
\text { not } \\
\text { assumed }\end{array}$ & 1.910 & .175 & $\begin{array}{l}2.327 \\
2.327\end{array}$ & $\begin{array}{r}38 \\
\\
36.44 \\
1\end{array}$ & .025 & $\begin{array}{l}5.750 \\
5.750\end{array}$ & $\begin{array}{l}2.471 \\
2.471\end{array}$ & .748 & 10.752 \\
\hline
\end{tabular}


Pengujian ini dilakukan dengan bantuan aplikasi SPSS 22 dengan taraf signifikansi 0.05 . Jika memiliki nilai sig. < 0.05 maka $\mathrm{H}_{0}$ ditolak $\mathrm{H}_{1}$ diterima. Berdasarkan tabel di atas diperoleh hasil uji hipotesis menggunakan uji $\mathrm{T}$ dua sampel independen dengan nilai sig. 0.025 nilai tersebut lebih kecil dari 0.05 maka dapat disimpulkan bahwa $\mathrm{H}_{0}$ ditolak $\mathrm{H}_{1}$ diterima. Jadi dapat diketahui perbedaan yang signifikan antara kelas eksperimen dan kelas kontrol. Maka terdapat pengaruh media wayang sukuraga terhadap keterampilan menulis deskripsi siswa.

Penggunaan media wayang sukuraga dapat membantu siswa dalam menulis deskripsi terlihat dari hasil uji hipotesis terdapat perbedaan yang signifikan antara kelas eksperimen dan kelas kontrol. Pada kelas eksperimen mendapatkan hasil yang lebih baik karena menggunakan media wayang sukuraga dalam keterampilan menulis deskripsi. Penggunaan media wayang sukuraga dapat membuat siswa lebih aktif karena dengan menggunakan media ketika pembelajaran maka dapat merangsang stimulus dan respon siswa. Sejalan dengan teori behavior menurut Nahar (2016: 65) yang menyatakan bahwa teori ini sangat menekankan kepada hasil belajar siswa yaitu adanya perubahan prilaku yang dapat diamati, diukur, dan dinilai secara konret. Didukung oleh pendapat Oktafiana Kiranida, (2019: 319) proses pembelajaran di sekolah dapat dikatakan sukses ketika siswa mengalami perubahan positif dari segi sikap, moral, dan tingkah laku. Dengan melihat kepada hasil menulis deskripsi rata-rata nilai siswa mengalami peningkatan maka terdapat perubahan prilaku siswa yang lebih baik setelah menggunakan media wayang sukuraga.

Media wayang sukuraga merupakan media yang digunakan untuk membantu siswa menggambarkan suatu objek sesuai pengamatan panca indra dan memperhatikan ejaan serta tata bahasa yang baik. Andani \& Hendratno (2015: 1343) mengatakan bahwa media pembelajaran diketahui dapat menjadi dorongan sebagai penyalur untuk memperjelas penyampaian materi. Keterampilan menulis termasuk ke dalam pembelajaran bahasa indonesia yang penting dan harus dikuasai oleh siswa karena dapat mengembangkan motorik halus. Perkembangan fisik, motorik, dan perseptual sangatlah penting untuk mengoptimalkan perkembangan kognitif siswa. Keterampilan motorik perlu dikembangkan agar anak mendapatkan stimulus yang terarah dan teratur karena anak yang mendapatkan stimulus dapat lebih cepat berkembang dibandingkan dengan anak yang kurang mendapatkan stimulus (Rohmatin \& Wulan, 2019: 173).

Ketika pelaksanaan tindakan siswa diajarkan untuk dapat menulis deskripsi dengan baik seperti teks deskripsi diberi judul yang tepat sesuai objek yang dideskripsikan, mengamati sebuah objek sesuai dengan hasil pengamatan panca indra, memperhatikan organisasi isi, serta menggunakan tata bahasa serta ejaan yang baik. penggunaan media wayang sukuraga dapat memberikan pengaruh positif kepada siswa dalam keterampilan menulis deskripsi. Dengan mengenalkan fungsi dari lima tokoh media wayang sukuraga yaitu mata, hidung, telinga, mulut, dan tangan dapat membantu siswa untuk mengamati objek sesuai dengan hasil pengamatan panca indra karena kelima tokoh tersebut sesuai dengan panca indra. Siswa mengamati objek menggunakan panca indra kemudia hasil pengamatannya dituangkan kembali dalam bentuk teks deskripsi.

Media wayang sukuraga selain dapat membantu siswa menulis deskripsi juga dapat menarik perhatian siswa karena mereka belum pernah melihat wayang sukuraga dan baru mengetahui wayang sukuraga. Didukung oleh pendapat menurut Dewi, Kristiantari, \& Ganing (2019: 279) yang mengatakan bahwa penggunaan media pembelajaran perlu diperhatikan dalam setiap proses belajar mengajar sehingga siswa tidak merasa bosan dalam mengikuti pelajaran dan hasil yang 
dicapai dapat maksimal. Media wayang sukuraga dianggap hal yang baru bagi siswa. Hal itu yang dapat membuat siswa terfokus dan tertarik kepada guru yang sedang menjelaskan. Siswa tertarik untuk memainkan wayang sukuraga sehingga membuat siswa aktif ketika proses pembelajaran.

\section{KESIMPULAN}

Berdasarkan kepada hasil penelitian serta pembahasan dapat ditarik kesimpulan bahwa media wayang sukuraga berpengaruh terhadap keterampilan menulis deskripsi. Media Wayang sukuraga memberikan pengaruh terhadap keterampilan menulis deskripsi siswa kelas V Madrasah Ibtidaiyah (MI) Rambay. Pengaruh media wayang sukuraga dapat dilihat dari hasil uji hipotesis dengan uji $\mathrm{T}$ dua sampel independen. Hasil uji tersebut menghasilkan nilai sig. 0,025. Nilai tersebut lebih kecil dari 0,05 maka uji hipotesisnya yaitu $\mathrm{H}_{0}$ ditolak $\mathrm{H}_{1}$ diterima artinya terdapat pengaruh media wayang sukuraga terhadap keterampilan menulis deskripsi.

\section{DAFTAR PUSTAKA}

Andani, R., \& Hendratno. (2015). Pengaruh Penggunaan Media Wayang Tokoh Terhadap Keterampilan Berbicara Siswa Sekolah Dasar. Jpgsd, 03, 1342-1353.

Dalman. (2016). Keterampilan Menulis. Depok: PT Raja Grafindo.

Dewi, N. N. K., Kristiantari, M. . R., \& Ganing, N. N. (2019). Pengaruh Model Pembelajaran Picture And Picture Berbantuan Media Visual Terhadap Keterampilan Indonesia. Journal Of Education Technology, 3, 278-285.

Dhavita, L., \& Damayanti, M. I. (2016). Pengaruh Penggunaan Media Papan
Magnet Terhadap Keterampilan Menulis Deskripsi Siswa Kelas III SD Hang Tuah 3 Surabaya. Jpgsd, 04(02), 161-172.

Halimatussakdiah. (2017). Pembelajaran Keterampilan Bahasa Indonesia (Bahan Ajar, Kritik Puisi, Kritik Novel, Kumpulan Puisi, Kumpulan Cerpen, Dan Naskah Drama). Medan: Unimed.

Ilina, S. L., Sutisnawati, A., \& Nurasiah, I. (2020). Pengembangan Media Wayang Sukuraga Terhadap Kreativitas Siswa Dalam Membuat Karya Imajinatif Di Kelas Rendah. Jurnal Ilmiah Pgsd Stkip Subang, Vi.

Juliana, A. D., Nurasiah, I., \& Wardana, A. E. (2019). Peningkatan Keterampilan Bercerita Melalui Media Wayang Sukuraga Berbasis 5 Karakter Di Kelas Tinggi. Journal Of Elementary Education, 3(2), 1-12.

Lailah, R., Fanani, A., \& Juniarso, T. (2020). Pengaruh Teknik Direct Object Terhadap Keterampilan Menulis Deskripsi Kelas IV Tema 4 Subtema 1 Pembelajaran 1 Sdn Menanggal 601 Surabaya. Jurnal Mitra Pendidikan, 4(4), 196-205.

Ludvi, \& Rukmi, A. S. (2013). Pemanfaatan Lingkungan Sekolah Sebagai Sumber Belajar Untuk Meningkatkan Keterampilan Menulis Deskripsi Pada Siswa Sekolah Dasar. Jurnal Penelitian Pendidikan Guru Sekolah Dasar, 1(2), 1-12.

Marsaid. (2016). Islam Dan Kebudayaan: Wayang Sebagai Media Pendidikan Islam Di Nusantara. 04.

Mila, M., \& Anafiah, S. (2021). Pengaruh Penggunaan Media Wayang Terhadap Keterampilan Menyimak Cerita Siswa Kelas V Di Sd 1 Petir Piyungan 
ISSN : 2303-1514 | E-ISSN : 2598-5949

Bantul. Trihayu: Jurnal Pendidikan $\mathrm{Ke}-\mathrm{Sd}-\mathrm{An}, \mathrm{7}(2), 1145-1150$.

Nahar, N. I. (2016). Penerapan Teori Belajar Behavioristik Dalam Proses Pembelajaran. Nusantara, 1 .

Nashruddin, M. D., \& Damayanti, M. I. (2013). Penerapan Metode Karya Wisata Untuk Meningkatkan Keterampilan Menulis Deskripsi Pada Siswa Sekolah Dasar. Jpgsd, 01(02), 1-8.

Oktafiana

Kiranida.

(2019).

Memaksimalkan Perkembangan

Motorik Siswa Sekolah Dasar Melalui
Pelajaran Penjaskes. Jurnal Tunas Bangsa, 6(2), 318-328.

Oktavianti, R., \& Wiyanto, A. (2014). Pengembangan Media Gayanghetum (Gambar Wayang Hewan Dan Tumbuhan) Dalam Pembelajaran Tematik Terintegrasi Kelas IV SD. Mimbar Sekolah Dasar, 1(1), 65-70.

Rohmatin, T., \& Wulan, B. R. S. (2019). Kemampuan Motorik Kasar Anak Sekolah Dasar Berdasarkan Perbedaan Status Ekonomi Keluarga. Jurnal Pendidikan Dasar Dan Pembelajaran, 9(2), 172-180. 